\title{
Urban Sprawl Mapping and Land Use Change Detection Analysis
}

\author{
M. Lenin Sundar" ${ }^{*}$, C.Arun Prasath ${ }^{\#}$, H.Elstin Rosario ${ }^{\#}$, K.Tamilselvan ${ }^{\#}$ \\ ${ }^{\#}$ Department of Civil Engineering, Sri Krishna College of Technology, Coimbatore - 641042, Tamilnadu, India \\ E-mail:*m.leninsundar@skct.edu.in; arunprasathcappa@gmail.com; elstinrosario1@gmail.com; smartworknicky@gmail.com
}

\begin{abstract}
Hasty changes occurred in the land use and land cover of Coimbatore city corporation, Tamil Nadu within 32 years span (1984 - 2016). Agricultural and forest lands are mainly converted into urban areas generally in an unplanned way which is making a change in dynamics of urban sprawl characteristics. The principal aim of this study is to use remote sensing data, geospatial tools to detect, quantify, analyze the urban land use changes of Coimbatore city, located in the western part of the Tamil Nadu. This study emphases on urban growth analyses and urban sprawl of Coimbatore city. In 2016, the jurisdiction of the Coimbatore Corporation was increased from 72 to 100 wards and five zones which consist area of $365.74 \mathrm{Sq} . \mathrm{Km}$. The corporation limit was extended from 29.25Sq.Km. in 1984 to $365.74 \mathrm{Sq}$. Km. in 2016 which has a growth of 1150 percent area of 1984 . Various GIS layers such as Ward, Zone, Corporation boundaries, Road and railway network, Waterbody, Stream, Major locations and Land use / land cover including built-up area; agricultural land; water bodies; industrial area; educational area, and Public \& Semi-public area were generated from Coimbatore Corporation map and Remote sensing imagery. This study revealed that Land use/Land cover areas such as agricultural, commercial, educational, industrial, public and semi-public, residential areas and water bodies occupied 9.38, 2.20, 5.0, 3.1, 1.02, 77.37 and 1.93 percentage areas of the city respectively in the year 2016. Land use pattern change was confirmed by field verification study in some places like near Gandhipuram, Brooke Fields, Avinashi Road, etc.
\end{abstract}

Keywords - remote sensing; GIS, urban sprawl; land use / land cover; change detection; coimbatore.

\section{INTRODUCTION}

The shape of Land use/Land Cover of an area is a result of natural and socio-economic factors and their utilization by human beings with time and space. The land is becoming a limited resource due to enormous agricultural and demographic pressure. So, information about land use / land cover and possible best usage of them is essential to plan for scarifying the increase in land demand of a city. These information may also assists in monitoring the dynamics of land use due to increase in population. Study of Land use and land cover change is useful for managing natural resources and monitoring environmental changes.

Changes in land use and land cover over 13 years, i.e. between 1995 and 2008 in Kafur local government area of Katsina state, Nigeria was studied [1]. This study used a paired t-test analysis for change detection along with remote sensing and GIS techniques.

The study has been done on land use, and land cover changes through remote sensing approach and GIS software using SOI taluk map of Kodaikanal and LANDSAT imageries of 2003 and 2008 [7].

An attempt is made to study the changes in land use and land cover using remote sensing approach using Land Sat imageries of October 1992 and November 2006 (14 years)in
Indra river watershed [4]. This study revealed that the forest area was increased from 15.01 percent in 1992 to 25.57 percent in 2006.

The study on urban sprawl and urban change of Salem Corporation for 1990 -2010was carried out using remote sensing and GIS [13]. It is found that the Old Suramangalam cluster or North West cluster extends from Andipatti to Burns colony. The Kalarampatti to NGGO colony / Chinnakollapatti extensions is the second cluster which occupies in the northeastern part of the corporation.

Urban sprawl change for 1973-2009from the Land sat images of Vijayawada city was studied [11]. The satellite images of MSS (1973), TM (1990), ETM+ (2001, 2011) which are rectified and registered in Universal Transverse Mercator (UTM) were obtained. Supervised classification of images was used for developing land use and land cover maps. Five land use classes had been identified such as urban (built-up), Waterbody, Agricultural land, Barren land, and Vegetation.

Changes in land use were analyzed spatial and temporal changes in land use of forest, farming and settlement using satellite imagery Landsat TM 7 and 8 (resolution $30 \mathrm{~m}$ ) that has been in the interpretation of 2004 to 2014 [2]. This study concluded that there had been a decline in the forest area of 128 ha (1.6\%), an increase in the mixed-farming area of 146 
ha $(16.1 \%)$, an increase in settlement area of 143 ha $(26 \%)$ for 11 years in Sub-watershed.

An analysis of spatial and temporal changes in land use of Dharmasraya from satellite images captured in 2004, 2009 and 2014 [3]. The result exhibited that there had been a decline in forest area from 2004 until 2014. The forest area which was initially in 2004 area is 161.141 ha, in 2009 decreased to 109.056 ha, and in 2014 decreased again to 94.146 ha. This decrease occurred in forest and non-forest areas.

Using remote sensing and GIS techniques urban sprawl of Gorakhpur City through the Land sat images of different years were studied [8]. Satellite data are found to be useful in mapping and quantifying the extent of the urban area in different time periods. A methodology arrived for better estimation of urban growth, and population using Land sat images of the various time.

On the basis of urban issues, urban growth and urban sprawl comparison were made between Kolkata and Haora Municipal Corporation [14]. Using remote sensing and GIS techniques built-up area of Kolkata and Haora were derived from three temporal satellite imageries on which several statistical techniques like Shannon Entropy, Weights of Evidence and Pearson's Chi-Square Method used to analyze the urban growth and sprawl.

Urbanization of Jaipur city and its impact on the natural environment includes remotely sensed data which was collected from LANDSAT, MSS for 1973, TM for 1998 and ETM+ for 2011 and other secondary data such as population data was collected from a census of India [9]. Land use/Land cover maps were prepared by hybrid classification (visual interpretation and unsupervised classification) and calculate the statistics for different years with the help of ERDAS software. Land use data showed that the built-up area is increasing at a faster rate and reached 19479.2 ha in 2011 from 1854.36 ha in 1973.

Land use/ Land cover types and its changes of Madurai city, Tamilnadu over the period of 26 years was studied by using remote sensing and GIS techniques [12]. ArcGIS, ArcMap, and ERDAS software were used in this study.

Research to study the land use changes in Haraz basin with an area of 677000 hectares in a 15 years period (1996 to 2011) was conducted using LANDSAT data [6]. Synthetic bonds were created using various enhancement methods and used for analysis. The results of this study revealed that $27 \%$ of the study area had been changed due to increase in population and human activities.

Spatio-temporal dynamics of land use / land cover of Hawalbagh block, Almora district, Uttarakhand, India for the period of 20 years (1990 to 2010) was studied by using satellite image of Landsat Thematic Mapper (TM) and GIS Techniques [10].In this study, more weight was given for digital change detection techniques.

A study evaluated land use/cover change (LCLU) and urban spatial expansion, from 1987 to 2013, in the Qom, Iran, using satellite images, field observations, and socioeconomic data [5]. Shannon's entropy was employed to measure the urban sprawl. CA-Markov model was used to simulate the LCLU change for the year 2022.
This study aims to obtain the latest land use map of Coimbatore city and analyze the urban sprawl of different years to calculate the urban area growth (1984 - 2016).

\section{MATERIAL AND METHOD}

\section{A. Study Area}

Coimbatore District is a district of Kongu region in Tamil Nadu state and is located in between Latitude $10^{\circ} 54^{\prime} 46.70^{\prime \prime} \mathrm{N}$ to $11^{\circ} 6^{\prime} 13.852^{\prime \prime N}$ and Longitude $76^{\circ} 5210.863 " \mathrm{E}$ to $77^{\circ} 346.66^{\prime} \mathrm{E}$. Coimbatore is the administrative headquarters of the district. It is one of the most industrialized districts and a significant textile, industrial, commercial, educational, agricultural and manufacturing hub of Tamil Nadu. The region is bounded in the east at $51 \mathrm{kms}$ from Tirupur district, in the north at $88 \mathrm{kms}$ from Nilgiris district, in the north-east at $100 \mathrm{kms}$ from Erode district. The administrative boundary of Coimbatore City is shown in Fig.1.
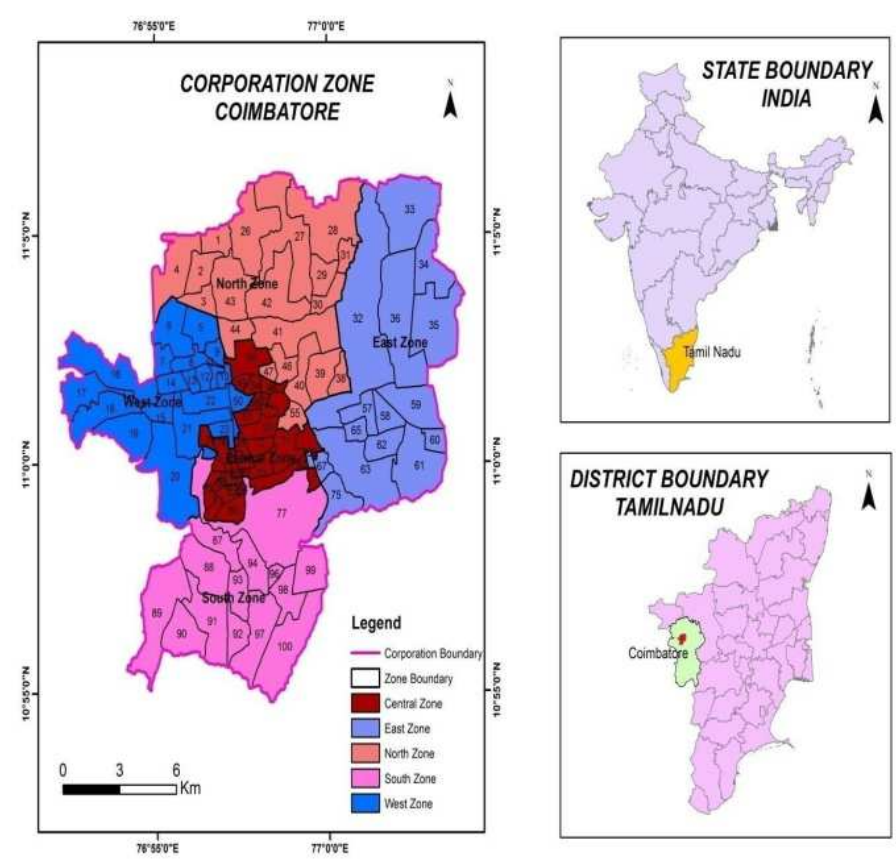

Fig. 1 Study Area (Coimbatore City Corporation)

Since Coimbatore is one of the industrial cluster, it has perceived remarkable growth, expansion, and developmental activities in the last few decades. Rapid urbanization has resulted in augmented land consumption which triggered the modification and alterations in land use / land cover status. It covers an area of $365.74 \mathrm{Sq}$. Km.in 2016. The population of the corporation is $21,36,916$ as per the census of 2011. It is essential to analyze and update the change in land use pattern at different time intervals for a fast-growing city like Coimbatore. Remote sensing and GIS techniques can be employed for this purpose.

Presently, Coimbatore Corporation is divided into 100 wards and five zones namely, east, west, south, north and central zones. 
Fig. 2 shows the details of the procedure adopted in this study as the flow chart.

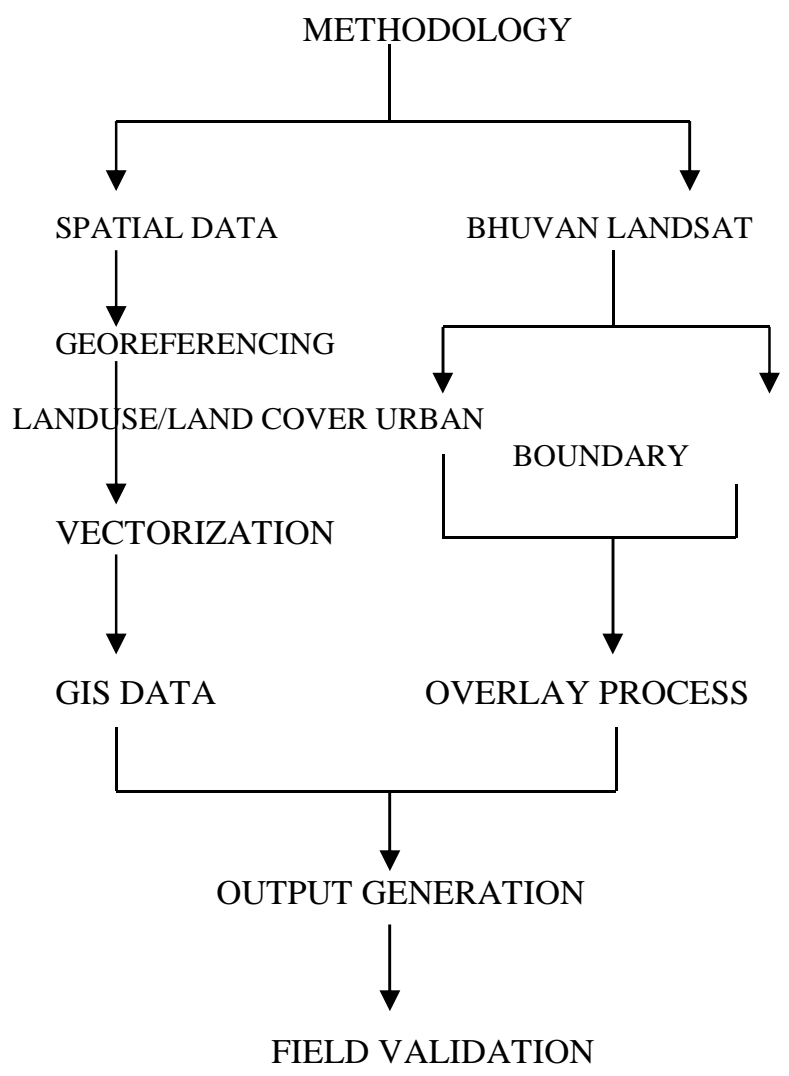

Fig. 2 Methodology - Flow Chart

\section{B. Spatial Data}

Spatial data represent the location, size, and shape of an object in Coimbatore city municipal corporation map. It includes attributes that provide more information about the entity that is being represented in a geographic information system (GIS).

\section{Georeferencing}

The internal coordinate system of a map can be related to a ground system of geographic coordinates, and it transforms or typically stored within the image file through there are many possible mechanisms for geo-referencing.

\section{Vectorization}

Vectorization can involve a series of procedures to achieve an acceptable raster to vector conversion. It can be simple as executing one command to generate the vector features.

\section{E.GIS data integration}

Data integrates the enabling interaction between data of many different types the raster surfaces can be combined vector data and many other formats to provide an integrated analysis environment.

\section{E. Bhuvan Landsat}

Bhuvan is an open source Indian Geo-platform of ISRO which provides satellite images of Indian States for various years. Landsat sensors have a moderate spatial-resolution.
We cannot see individual houses on a Landsat image, but we can see large man-made objects such as highways. This is an essential spatial resolution because it is coarse enough for global coverage, yet detailed enough to characterize humanscale processes such as urban growth.

\section{F. Land use/Land Cover}

Land Use/Land Cover data refers to data that is a result of classifying raw satellite data into "land use and land cover" (LULC) categories based on the return value of the satellite image. Land use land cover maps were prepared using a supervised classification technique.

\section{G. Urban Boundary}

Urban map for Coimbatore municipal Corporation boundary has been taken to detect the changes of the year1984-2016.

\section{H. Overlay Process}

Overlay in a GIS operation that superimposes multiple maps with universal coordinate system together it creates the composite by combining different data sets.

\section{Output Generation}

The study area of Coimbatore Municipal Corporation had declared the land use and land cover of urban sprawl variation of the year 1984-2016.

\section{J. Field Validation Study}

Field validation is the physical, on-site verification of the pixels that are transmitted via satellite as a result of remote sensing and processed into images and maps depicting particular features of a place. The experience of a place/this place, depending upon the context could be only the pixel displaying colors representative of invisible bands of light and that political and economic decisions about this place might be made based solely on the information of the pixel. To seek a practice that compares information of an actual locale with the compressed version of the pixel to create hybrids of scientific and local subjectivities, at times of working collaboratively with others where the ground truth of the pixel supports the notion and practice of local authority.

\section{RESULTS AND DISCUSSION}

The loss in agricultural land, open space, and ecologically sensitive habitats impacts can be known as Sprawl. Due to population increases or expansion of a city to accommodate the city growth is considered as sprawl. Commonly sprawls take place on the urban fringe particularly at the edge of an urban area or along the highways. The Urban Boundary of 1984 was overlaid with the google earth pro image of 1984 and found that it was approximate and same as the image available and so this method has been used for justification process and this is shown in Fig 3. 


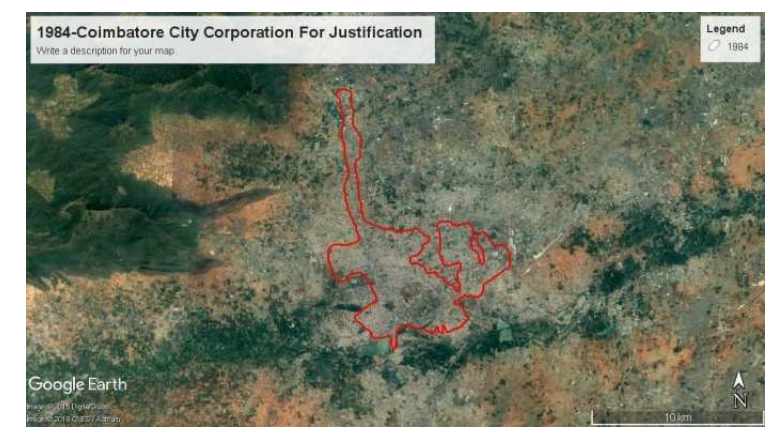

Fig.3 Coimbatore Corporation at 1984 with google earth pro boundary

The urban sprawl of Coimbatore from 1984-2016 is shown in Fig 4 to 8.

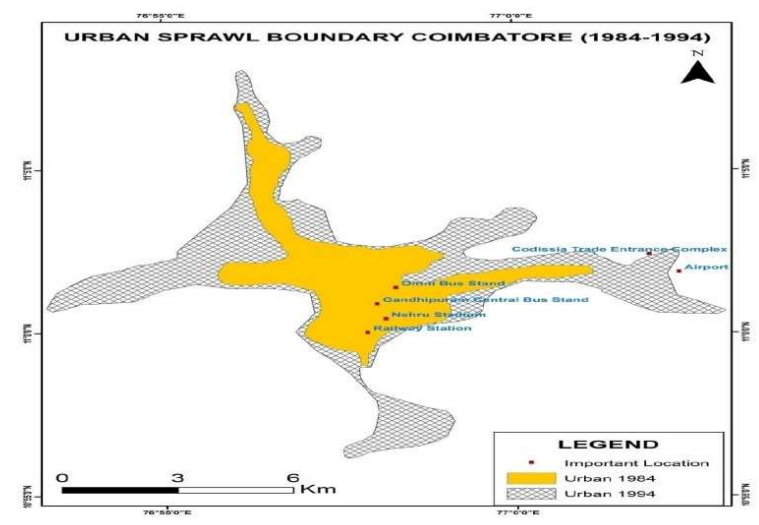

Fig. 4 Urban boundaries of Coimbatore in during 1984-1994

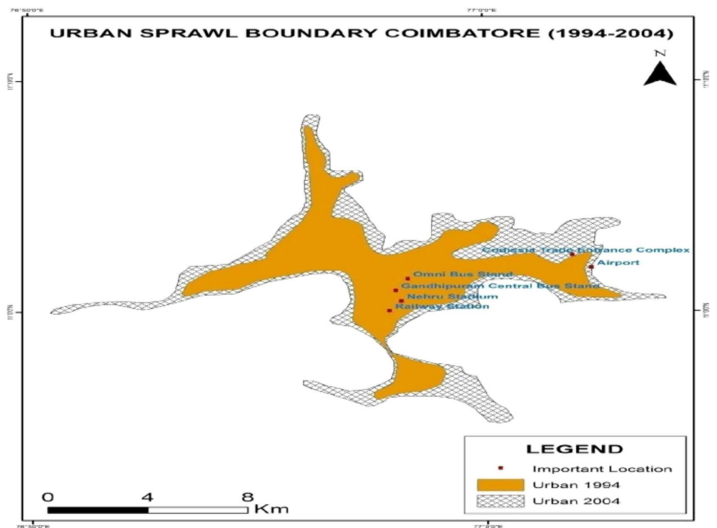

Fig.5 Urban Sprawl Boundary Coimbatore (1994-2004)

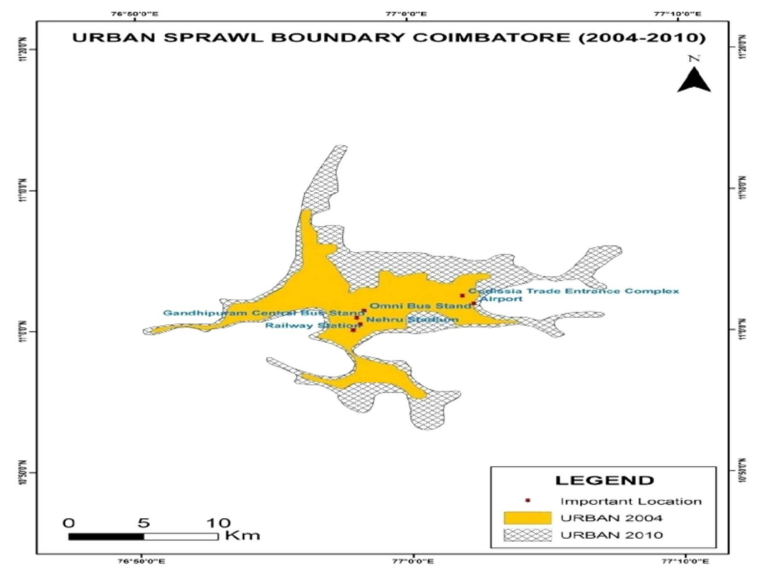

Fig. 6 Urban Sprawl Boundary Coimbatore (2004-2010)

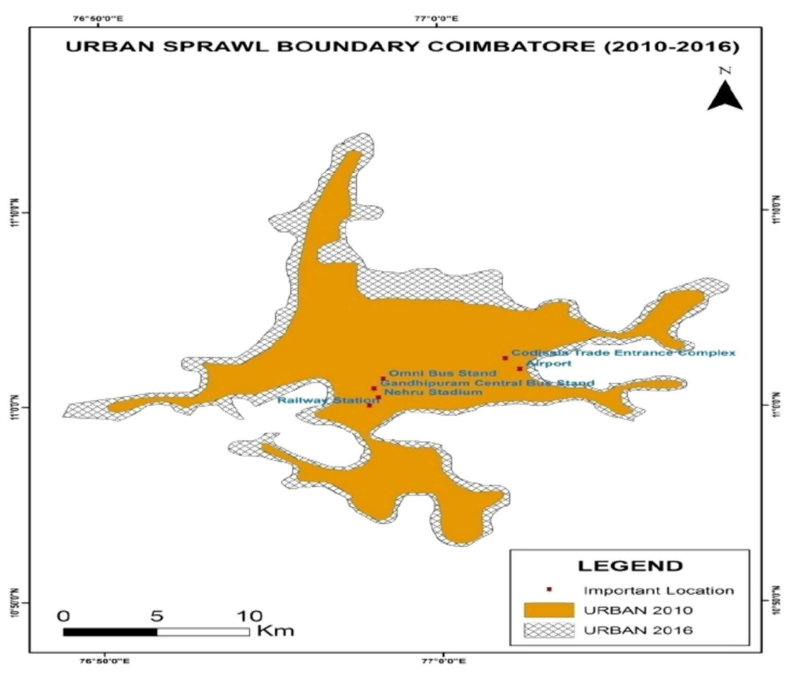

Fig.7 Urban Sprawl Boundary Coimbatore (2010-2016)

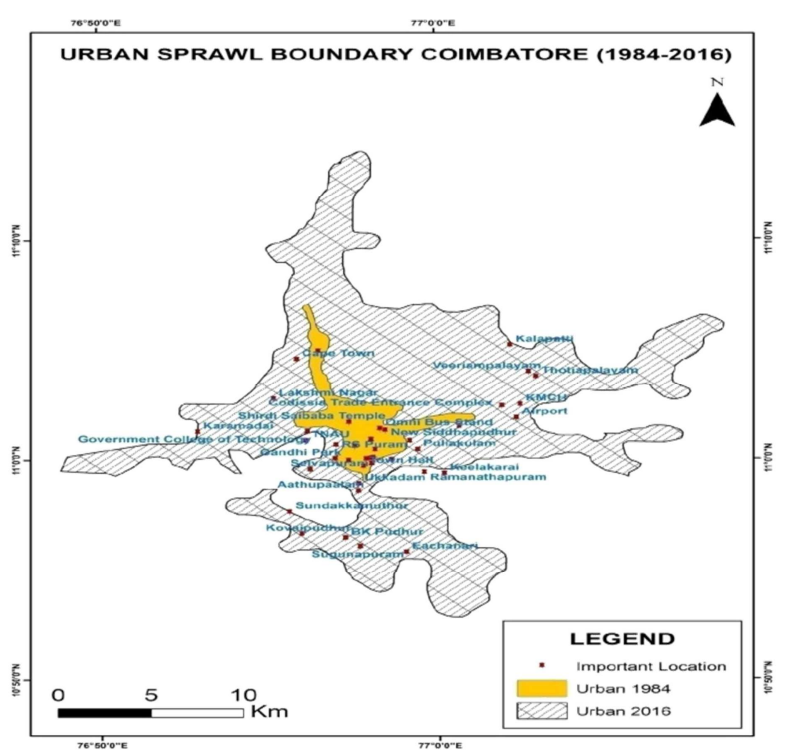

Fig.8 Urban Sprawl Boundary Coimbatore (1984-2016)

The corporation area during the period of $1984-2016$ and their percentage of increase is presented in Table 1.

TABLE I

URBAN SPRAWL OF COIMBATORE CORPORATION

\begin{tabular}{|l|l|l|l|}
\hline S. No. & Year & Area (Sq.Km) & $\begin{array}{l}\text { Percentage of } \\
\text { increase }\end{array}$ \\
\hline 1 & 1984 & 29.249 & 100 \\
\hline 2 & 1994 & 69.044 & 136 \\
\hline 3 & 2004 & 133.962 & 358 \\
\hline 4 & 2010 & 252.627 & 764 \\
\hline 5 & 2016 & 365.74 & 1150 \\
\hline
\end{tabular}

The study area covers approximately 29.249 sq. km. geographical extent in 1984 by referring to Landsat imagery. When compare the Landsat images of 1984 to 1994, most of the agricultural lands are converted into settlement, industry and commercial use as urban sprawl. In the span of 10 years, the Coimbatore city spread additionally 39.795 sq. km. area 
and 136 percentage in the surroundings of the existing urban boundary (Fig.4).

The study area covers approximately 69.044 sq. km. Geographical extent in 1994 by referring to Landsat imagery. When compare the urban sprawl from 1994 to 2004 in Landsat images, most of the agricultural lands are converted into settlement, industry and commercial use. In the span of 10 years, the Coimbatore city spread additionally 64.918 sq. $\mathrm{km}$. the area in the surroundings of the existing urban boundary of 1994 (Fig.5).

The study area covers approximately 133.962 sq. km. geographical extent in 2004 by referring to Landsat imagery. When compare the urban sprawl from 2004 to 2010 in Landsat images, most of the agricultural lands are converted into settlement, industry and commercial use. In the span of 7 years, the Coimbatore city spread additionally 118.665 sq. $\mathrm{km}$. the area in the surroundings of the existing urban boundary of 2004 (Fig.6).

The study area shelters approximately 252.627 sq. km. Geographical extent in 2010 by referring to Landsat imagery. When compare the urban sprawl from 2010 to 2016 of Landsat images, most of the agricultural lands are occupied for settlement, industry and commercial use. In the span of 6 years, the Coimbatore city spread additionally 113.112 sq. $\mathrm{km}$. the area in the surroundings of the existing urban boundary of 2010 (Fig.7).

The overall variation of the city area over the 32 years of the period is from 29.249 to 365.74 sq.km (around 1150 percentages) between the years 1984 and 2016 as shown in Fig. 8.

Land use/Land cover includes the management and alteration of natural environment or wilds into built environment, for instance, settlements and semi-natural habitats and others. In our study area totally seven land use / land cover features were visually interpreted from IRS P6 L4MX and those features referred from DTCP Coimbatore Master Plan map. Land use / Land cover map of Coimbatore for the year 2016 is given in Fig.9. Necessary field checks were done to ensure the land use classes wherever necessary. It is presented in Table 2.

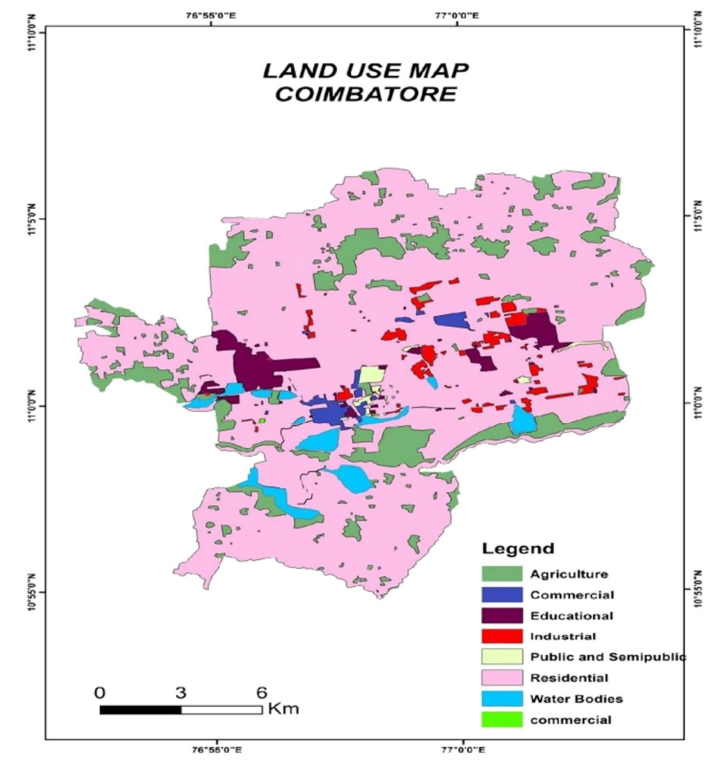

Fig. 9 Land Use/ Land Cover of Coimbatore Corporation (2016)
TABLE II

LAND USE/ LAND COVER AREAS DURING 2016

\begin{tabular}{|l|l|l|l|}
\hline $\begin{array}{l}\text { S. } \\
\text { No. }\end{array}$ & $\begin{array}{l}\text { Land use / Land } \\
\text { cover }\end{array}$ & $\begin{array}{l}\text { Area } \\
\text { (Sq.Km.) }\end{array}$ & Percentage \\
\hline 1 & Agricultural area & 34.305 & 9.38 \\
\hline 2 & Commercial area & 8.046 & 2.20 \\
\hline 3 & Educational area & 18.287 & 5.00 \\
\hline 4 & Industrial area & 11.337 & 3.10 \\
\hline 5 & $\begin{array}{l}\text { Public and Semi Public } \\
\text { area }\end{array}$ & 3.731 & 1.02 \\
\hline 6 & Residential area & 282.973 & 77.37 \\
\hline 7 & Water Bodies & 7.060 & 1.93 \\
\hline
\end{tabular}

Development of New urban region happened mainly towards north, north-east and south direction along the main transport routes of the city. This development arises mainly on vegetation and agricultural lands. This study affords a methodology for estimating urban growth and population using various Land uses with time. Spatial inputs are made with satellite images and GIS.This study can be used for predicting future land uses expansions when old land use data is not available. This is useful for urban planning authorities in developing countries. Remote sensing and GIS techniques can assist more in monitoring urban sprawl than conventional techniques.

The results of this study were obtained on the basis of Image classification and interpretation. The urban development of Coimbatore city shown the development of urban lands changed lot on the other parts of the city. Multidate satellite image interpretation facilitated in the preparation of urban sprawl map. The agricultural / Scrub area decreases due to the conversion of urban land use.

Field verification study is carried out in some places like near Gandhipuram, Avinashi road, etc. The changes happened at Brooke Bond road is shown in Fig. 10.

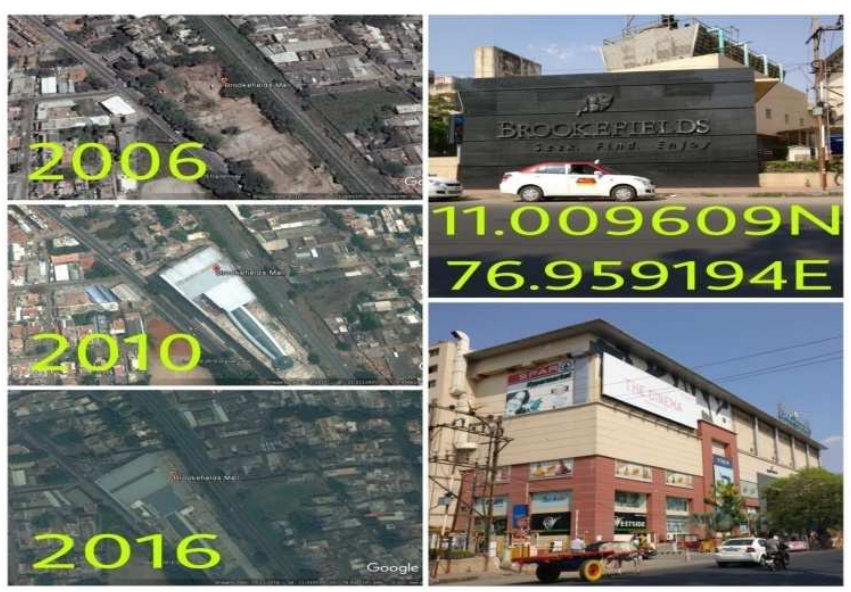

Fig. 10 Changes detected at Brooke Fields, Brooke Field, Coimbatore

Brooke fields, where located at a distance of $2.9 \mathrm{Kms}$ from Gandhipuram,Coimbatore. At 2006, only a few buildings were constructed in Dr.Krishnasamy road, and Brooke fields were not constructed. Brooke fields were newly constructed in the agricultural land. Now in 2016, there are some more newly constructed buildings are come, and that area is developed a lot. Other places where new residential clusters are developed such as Vedapatti, Kalapatti Road, Sathyamangalam Road, 
Ramanathapuram, Idigarai, and Edayarpalayam were also visited personally, and the same were cross verified with Google maps.

\section{CONCLUSIONS}

From this study, it is revealed that Land use/Land cover areas such as agricultural, commercial, educational, industrial, public and semi-public, residential areas and water bodies occupied 9.38, 2.20, $5.0,3.1,1.02,77.37$ and 1.93 percentage areas of the city respectively in the year 2016 .

In 1984 the urban sprawl around 29.25 Sq. Km. and the boundary has linear extension in the north of Mettupalayam road and in the east of Avinashi road. In 10 years (1994) span the urban sprawl increases approximately $136 \%$ (69.044 Sq. Km.) mostly eastern, western and southern part of the urban. In the northern part, very least area was extended. In 2004 urban area expanded around $358 \%$ (133.962 Sq.Km.) in the area of eastern, western and southern part of the city. Urban developed the maximum in the north-eastern and southern part of the city in the year 2010. Presently, Coimbatore urban covers an area of $365.74 \mathrm{Sq} . \mathrm{Km}$. in 2016.

In 2016, the jurisdiction of the Coimbatore Corporation was expanded to 100 wards and five zones such as East, West, Central, North, and South. The thecorporation limit was extended from 29.25Sq.Km in 1984 to 365.74 Sq.Km. in 2016 which has a growth of 1150 percent area of 1984.

\section{ACKNOWLEDGMENT}

The authors would like to express their sincere gratitude to the Management, the Principal and the Head of Civil Engineering department of Sri Krishna College of Technology, Coimbatore, for the support and facilities provided to pursue this study. Also, the authors intend to express their heartfelt thanks to the Editor in-chief and referees of this journal for their effort and support in publishing this paper in precise manner.

\section{REFERENCES}

[1] Abbas I.I., Muazu K.M. and Ukoje J.A., "Mapping Land Use-land Cover and Change Detection in Kafur Local Government, Katsina, Nigeria (1995-2008) Using Remote Sensing and GIS", Research Journal of Environmental and Earth Sciences, Vol. 2, pp.6 - 12, Jan. 2010 .

[2] Edwin, Amrizal Saidi, Aprisal, Yulnafatmawita and Ita Carolita, "Spatial and Temporal Analysis of Land Use Change for 11 years(2004-2014) in Sub-Watershed Sumpur Singkarak", International Journal on Advanced Science Engineering Information Technology, Vol. 5, pp.326 - 329, Sept. 2015.
[3] Edwin and Yuzirwan, "Evaluation of Land Use Change in the District Dharmasraya", International Journal on Advanced Science Engineering Information Technology, Vol. 6, pp.97 - 103, Jan. 2016.

[4] Gajbhiye S. and Sharma S.K., "Land use and land cover change detection of Indra river watershed through remote sensing using multi - temporal satellite data", International Journal of Geomatics and Geosciences, Vol. 3(1), pp.89-96, July 2012.

[5] Hassan Mohammadian Mosammam, Jamileh Tavakoli Nia, Hadi Khan, Asghar Teymouri and Mohammad Kazemi, "Monitoring land use change and measuring urban sprawl based on its spatial forms, the case study of Qom city", The Egyptian Journal of Remote Sensing and Space Sciences, Vol.20, pp. 103 - 116, 2017.

[6] Naser Ahmadi Sani, Karim Solaimani, Lida Razaghnia and Jalal Zandi, "Land use change detection using Remote Sensing and GIS", International Journal of geological and Environmental Engineering, Vol.10, No.3, pp. 373 - 377, 2016.

[7] Prakasam C., "Land use and land cover change detection through remote sensing approach: A case study of Kodaikanal taluk, Tamilnadu", International Journal of Geomatics and Geosciences, Vol. 1, pp. 150 - 158, Sept. 2010.

[8] Priyanka Dubey and Dilip Kumar, "Urban Sprawl and its Impact on Urban Environment", IOSR Journal of Mechanical and Civil Engineering (IOSR-JMCE), Vol. 9, pp. 26-31, Nov. 2013.

[9] Rajpoot Pushpendra Singh, Kumar Ajay and Pandey Gyanendra Kumar, "Assessment of Urban Sprawl and its Impact on Natural Environment in and around Jaipur city, Rajsthan, India", International Research Journal of Earth Sciences, Vol. 2, pp. 1-6, April 2014.

[10] Rawat J.S. and Manish Kumar, "Monitoring land use/cover change using remote sensing and GIS techniques: A case study of Hawalbagh block, district Almora, Uttarakhand, India”, The Egyption Journal of Remote Sensing and Space Sciences, Vol.18, pp.77-84, 2015

[11] Sundarakumar K., Harika M., Aspiya Begum S.K., Yamini S., and Balakrishna K., "Land use and Land cover change detection and urban sprawl analysis of Vijayawada city using Multitemporal Landsat data", International Journal of Engineering Science and Technology, Vol. 4, pp.170 - 178, Jan. 2012.

[12] Tamilenthi S., Arul P. and Chandramohan K., "Detection of urban change and urban sprawl of Madurai City, Tamilnadu using GIS and RS", Journal of Environment Protection and Sustainable Development, Vol.1, No.3, pp.107-120, May 2015.

[13] Tamilenthi S. and Baskaran R., "Detecting urban change of Salem City of Tamilnadu, India from 1990 to 2010 using Geospatial Technology", International Transaction Journal of Engineering, Management \& Applied Sciences \& Technologies, Vol.2, pp.183 195, Mar. 2011.

[14] Tusi Das, Sabari Chakraborty and Kaberi Samanta, "Urban sprawl and urban growth detection analysis: A comparative study of Kolkata municipal corporation and Haora municipal corporation",International Journal of Geomatics and Geosciences, Vol. 7, pp.82 - 92, Aug.2016. 